\title{
Determinants of the early initiation of breastfeeding in the Kingdom of Saudi Arabia
}

\author{
Adam E. Ahmed ${ }^{1,2}$ and Osama A. Salih ${ }^{3^{*}}$
}

\begin{abstract}
Background: National surveys in the Kingdom of Saudi Arabia continue to show rates of breastfeeding below global recommendations. Delay of timely or early initiation of breastfeeding is common in the community. Current approaches are not addressing the major constraints. Objectives of this study were to study the pattern and determinants associated with the early and delayed initiation of breastfeeding practices among infants aged less than 24 months. Also to assess regional differences to facilitate targeted actions.
\end{abstract}

Methods: This cross-sectional study was conducted from May to August 2016, based on a sample of 1700 mothers of children aged less than 24 months. The sample was randomly selected from over 165 health centers distributed across the country, at least 33 centers in each of the five geographical regions. World Health Organization standardized questionnaire for infant and young child feeding indicators was used to prepare structured questionnaire (in English translated later to Arabic) to collect the information on breastfeeding along with general sociodemographic data.

Results: The breastfeeding initiation rate was $97.3 \%$ (1559/1700 mothers). Only 8.3\% (141) of mothers never breastfeed their children. Early initiation of breastfeeding within $1 \mathrm{~h}$ of birth was $43.6 \%$ (742) among all mothers surveyed while, breastfeeding initiation rates for $1-24 \mathrm{~h}$ and that for more than $24 \mathrm{~h}$ were 27 and $21 \%$ respectively. The overall prevalence of early initiation of breastfeeding (43.6\%) is considered 'fair'. Regional variation showed poor prevalence 26\% (79/300 mothers) in Northern region; fair 38.4\% (192/500 mothers), 45\% (135/300 mothers), 49\% (148/300 mothers) in the Central, Western and Eastern regions respectively; and good 63\% (188/300 mothers) in the Southern region. Significant associations were indicated between early initiation of breastfeeding and mode of delivery, knowledge of the mother about the right time for early initiation, receipt of breastfeeding information, the region of residence, and educational level of the mother.

Conclusion: Whilst some barriers to breastfeeding initiation manifest similarity across the regions some factors were context-specific thus, tailored interventions are imperative. Appropriate behavior change interventions, are needed attain optimal breastfeeding practices.

Keywords: Breastfeeding, Determinants, Early initiation, Saudi Arabia

\footnotetext{
*Correspondence: salihosamasalih2015@gmail.com

${ }^{3}$ Department of Community Health, College of Applied Medical Sciences,

King Saud University, Riyadh, Kingdom of Saudi Arabia

Full list of author information is available at the end of the article
}

(c) The Author(s). 2019 Open Access This article is distributed under the terms of the Creative Commons Attribution 4.0 International License (http://creativecommons.org/licenses/by/4.0/), which permits unrestricted use, distribution, and reproduction in any medium, provided you give appropriate credit to the original author(s) and the source, provide a link to the Creative Commons license, and indicate if changes were made. The Creative Commons Public Domain Dedication waiver (http://creativecommons.org/publicdomain/zero/1.0/) applies to the data made available in this article, unless otherwise stated. 


\section{Background}

The Kingdom of Saudi Arabia (KSA) has a population of 32 million and a male:female distribution of $57: 42 \%$ respectively [1,2]. At least $24.8 \%$ of the total population are age less than 15 years while the people who ranges between 15 and 64 years old represent $72 \%$, and only $3.2 \%$ are older than 65 years. About one quarter (24.8\%) of the population live in Riyadh, the capital city of KSA, the Western region (Jeddah, Makkah and Taif) is inhabited by another $24 \%$; the Eastern province by $13.3 \%$ and the remaining spread over the rest of the country [2].

What had been customarily a breastfeeding culture in Saudi Arabia, was disrupted with the great influx of oil wealth in the 1970's and 1980's [3]. The country witnessed massive advancements in socioeconomic status and became a target for breast milk substitutes industry. This coupled with other social and economic factors has caused considerable change in the original pattern of breastfeeding in recent decades in the country [3].

Breastfeeding is recognized globally as a vital public health issue with vast health, social and economic implications. It is manifested that, the recommendation for optimal breastfeeding practices in the Kingdom of Saudi Arabia (KSA) is based firstly on the Holy Quran, and then the commitments to the objectives of the global strategy for the Infant and Young Child Feeding (IYCF) and the recommendations of the World Health Organization (WHO) and United Nations Children's Funds (UNICEF) [3-5]. Yet, current surveys remain to show that, poor breastfeeding practices (e.g. the delay of the early initiation of breastfeeding) are common in the Saudi communities [6-8].

The benefits of initiation of breastfeeding within $1 \mathrm{~h}$ of birth has long been recognized, understood and well documented [9-11]. The WHO and the UNICEF recommend that children initiate breastfeeding within the first hour of birth and be exclusively breastfed for the first 6 months of life [5]. Recent global reports $[5,12]$ indicate that, most of the world's newborns are waiting too long to begin breastfeeding, and in 2017 alone, an estimated 78 million newborns had to wait more than $1 \mathrm{~h}$ to be put to the breast.

Recent meta-analysis $[13,14]$ investigate the links between the delayed breastfeeding initiation and infant survival, results indicated that newborns who began breastfeeding between 2 and $23 \mathrm{~h}$ after birth had a 33\% greater risk of dying compared with those who began breastfeeding within $1 \mathrm{~h}$ of birth [13]. Also, among newborns who started breastfeeding $24 \mathrm{~h}$ or more after birth, the risk was more than twice as high.

When breastfeeding is delayed after birth, the consequences can be life-threatening, and the longer newborns are left waiting, the greater the risk [5]. Early initiation of breastfeeding (EIBF) is an indicator defined according to $\mathrm{WHO}$ as the proportion of children born in the last 24 months who were put to the breast within $1 \mathrm{~h}$ of birth $[10,11]$. However, for initiating breastfeeding within the first hour of life, mothers need adequate support, direction and encouragement on positioning and feeding their newborns. Nevertheless, it is indicated that once the decision to breastfeed is made, different social and behavioral factors influence the duration of breastfeeding and its exclusivity [15]. For instance, in some countries there are cultural practices that involve feeding newborns supplemental foods or drinks, or having an elder family member give the newborn a specific food or liquid, or having health professionals routinely give the newborn a specific liquid, such as sugar water or infant formula [16].

Other factors and reasons why newborns are missing out on breastfeeding in the first hour of life include outdated practices in health facilities such as immediate separation of mothers and babies after birth. The dearth of knowledge about breastfeeding after a caesarean delivery that can lessen the probability of immediate skin-to-skin contact and hence reduce the early initiation of breastfeeding $[17,18]$.

In the context of the Kingdom of Saudi Arabia, a national infant and young child feeding/breastfeeding policy has been officially adopted/approved by the government [3]. Yet, there is presently an absence of a comprehensive surveillance system that shares and compiles data nationally, lack of community-based support centers easily accessible to mothers and absence of strategic plans for national implementation of IYCF. Moreover, the national Saudi Code of Marketing of Breast Milk Substitutes needs updating and revision [3].

The current practice of breastfeeding Saudi infants showed high (>90\%) prevalence of breastfeeding initiation at birth [19-23] compared to about 31\% in the 1990s [24]. However, the initiation of breastfeeding rate tends to decline dramatically to low rates, because of the influence of many factors including (among many) mother's age and education, parity and rooming in. The majority of the available literature regarding breastfeeding in KSA focuses on the rate of initiation rather than timely or early initiation of breastfeeding. For instance, a nationwide nutritional survey (2004-2005) of a sample of 5339 Saudi children was performed as part of the Health Profile for Saudi Children and Adolescents Projects. Results showed that, 4889 (91.6\%) received breast milk at birth however, initiation of breastfeeding was delayed beyond $6 \mathrm{~h}$ after birth in $28.1 \%$ of the infants [25]. A cross-sectional observational study in Saudi Arabia in 2015 revealed that, $94.4 \%$ of the Saudi mothers were successful in initiating breastfeeding on the first day of delivery [19]. According to El Mouzan et al. and Al Juaid et al. $[25,26]$ initiation rates among Saudi mothers were high (mostly above 90\%), but a few studies reported low rates of timely initiation (within the first hour). 
Regarding the prevalence of the early or timely initiation of breastfeeding, the official figure reported by the World Breastfeeding Trend Initiative (WBTi) was 11.7\% $[3,27]$. A recent study in Mecca, Saudi Arabia showed that, early initiation of breastfeeding $(<1 \mathrm{~h})$ was observed in $38.1 \%$ mothers, and that $42.7 \%$ mothers de-

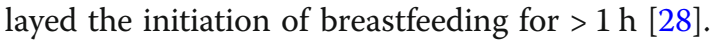

It is clear from the modest literature available regarding breastfeeding in KSA that, there is inconsistency in the outcomes of the studies tackling the issue of breastfeeding practices in KSA but particularly, the early initiation of breastfeeding. None of the published literature were able to diagnose and explain the genuine reasons behind poor timely/early initiation of breastfeeding in the kingdom of Saudi Arabia. There were many literature gaps that need critical investigation regarding the transition shift in behavioral and social norms of the people as well as the not conforming to the international health and nutrition agreements.

\section{Methods}

After obtaining the required study approvals, the research team conducted this comprehensive cross-sectional, in-depth, health facility-based survey of Saudi mothers with infants less than 24 months of age from May to December 2016. The study was performed at primary health care centers (PHCCs) in five major cities (Riyadh, Hail, Jazan, Jeddah and Dammam) representing the different geographical regions (Central, Northern, Southern, Western and Eastern) of the Kingdom of Saudi Arabia (KSA).

Sample of 1700 mothers of infants aged 0 to less than 24 months were selected from the designated cities. A network of over 500 PHCCs is widely distributed all over the country, each PHCC has a well-defined catchment area and population therefore, each PHCC was considered as a cluster. Using a stratified multistage cluster sampling design [29], thirty-three (33) primary health care centers were selected from each region both from urban and rural areas (26 urban and 7 rural centers) based on the urban/rural ratio of $80 / 20$ reported by the Saudi general authority for statistics [2]. More specifically, at least one PHCC located in each of the north, south, east, west and central areas of each region was randomly selected after stratification by population density, socioeconomic status and geographical location was carried out. Mothers fulfilling the eligibility criteria were enrolled in the study from each health center during the data collection period until the required sample size was reached.

The inclusion criteria were; mothers aged $15-49$ years, who were attending one of the designated PHCCs, having a child less than 24 months of age, and being Saudi national. There were no distinctions made for the inclusion criteria regarding the body mass index of the mother and/or whether the child was term or preterm.

While exclusion criteria were; mothers with child older than 24 months and mother who had twins. The eligible mothers were approached in person and invited to an individual interview after they had received a proper orientation. Participants were fully informed about their rights to participate, and the right to withdraw, without any consequence, at any time prior to or at any point, during or after the start of the interview. Written informed consents were obtained from all participants and confidentiality was assured. Participants were assured that any information provided will be used only for research purposes.

\section{Data collection}

The in-depth interviews with the selected mothers in each PHCC was carried out by experienced Arabic-speaking (Saudi national), female, health personnel (nurses and dietitians) and medical staffs (doctors,) working at each PHCC. Average of twenty to thirty data collectors were selected from the working staff in each region with the help and permission of the local health authorities. Specially designed training programs ( 2 days training) on the study tools were conducted by the investigators for the data collectors in each region prior to field survey. The data collection was carried out using an interview-administered questionnaire. The questionnaire was prepared in English with guidance from the WHO [4] standardized questionnaire for infant and young child feeding indicators. The questionnaire was translated into Arabic with back translation to check for reliability.

A Pilot survey was carried out among thirty-two Saudi mothers in four randomly selected health centers in Riyadh region, representing the four geographical locations of the city, with the purpose of testing the questionnaire which had been designed, and the pilot study participants were excluded from the final study sample. The generated data from the pilot survey was processed and analyzed, accordingly, questionnaire was revised, modified and edited. The questionnaire was checked for item flow, order, skip patterns, timing, and time needed for completion. The estimated time for completion was approximately $20 \mathrm{~min}$. The questionnaire had three components: demographic data (for the infants, mothers and fathers) including age, education and employment; breastfeeding practice related data, including initiation of breastfeeding, exclusive breastfeeding, reasons and barriers for not or delayed initiation of breastfeeding, prelacteal (defined as any food except mother's milk provided to a newborn infant before initiating breastfeeding), type of milk given, introduction of solid or semi solid food, and on demand feeding; and health service related data, including mode of delivery, pre and 
postnatal services, feeding discussion during antenatal checkup, receiving breast milk substitute advertisements and others.

\section{The structure of the questionnaire}

This in-depth questionnaire used for collecting the study data consisted of the following main units, the first unit (comprised of two sections). Section A, for collecting socioeconomic characteristics [age (month and year), profession, level of education, marital status and monthly income] for the household head, mother and or caregiver. Section B, for the child background information [name, gender, date of birth, age, sex, method of delivery, birthweight (health card) and age of the previous child if any]. Additional questions were also included within this unit such as family size, whether the mother is working fulltime, part-time or not working and how many hours the mother stays away from the child (if she is working). In addition, questions regarding the child's health situation (presence or absence of chronic diseases), and the status of vaccination situation were also enquired. The second unit of the questionnaire collected information regarding the early initiation of breastfeeding (EIBF). The following questions were asked to mothers: did you ever breastfeed (child name)? If the answer was "Yes", the following questions were asked, how long after birth did you first put (child name) to the breast? The answers were reported as follows, immediately after birth; less than $1 \mathrm{~h}$; less than $24 \mathrm{~h}$ (number of completed hours from 01 to 23 was recorded); $24 \mathrm{~h}$ or more (number of completed days was record). If the answer was "No" for the question 'did you ever breastfeed the child?', mothers were asked about the reason for not breastfeeding the child, then responses were recorded (baby sickness, mother sickness, have not enough milk, breastfeeding is too painful, breastfeeding is too stressful, body image, returning to work soon and other reasons). If the mother delayed breastfeeding for "less than 24 hours" or "more than 24 hours" she was then asked for the reason(s), and responses were then recorded (child given prelacteal feed, type of delivery, place of delivery, late discharge from the nursery, mother sickness, cultural factors and/or other reasons). The third unit of the questionnaire concerned with the administration of the infant and young child feeding. Questions in this unit were "what was your baby's first feed?" (breast milk or colostrum, infant formula, herbs water, Glucose water, dates water, plain water and others). Mothers were also asked whether the child was breastfed yesterday (day or night) and if the child was breastfed from his mother or other method was used to fed breast milk (breastfed by another mother, given breast milk by spoon, cup, bottle or some other way). Mothers were also asked if the child was given oral rehydration solution (ORS) the day before the interview during a day and night? The other two units of the questionnaire were the knowledge attitudes and practices unit, and prenatal and postnatal care unit.

\section{Data management}

For technical and logistic reasons, the field surveys were conducted in the five regions of the country, one at a time, during the period from May to August 2016. In the process of the preparation for the study surveys, the study team held orientation meetings with the health officials at the Federal Ministry of Health (FMOH), followed by a series of similar meetings with officials and the staff of the "women and child health" departments at the regional Ministries of Health during the pre-visits conducted to each region. These meetings reflected to the regional Ministries, the commitment and approval of the study by the FMOH, demanding facilitation and coordination with the study team. Moreover, updated information about the population density, socioeconomic status, geographical locations, characteristics of the local population, and logistic issues were collected, shared, discussed and managed through local committees specially formulated for the purpose of this study in each region. These committees assisted in selecting the data collectors and facilitating their training. At the end of the survey with mothers in each region, the investigators meet with the data collectors for the feedback on the survey process and to collect their finished work.

\section{Data analysis}

The data generated by the questionnaire were assigned appropriate codes, processed, analyzed, interpreted and reported for each region and for the country. Analysis was performed on the collected data using the Statistical Package for the Social Sciences (SPSS) program, version 21.0.

The early initiation of breastfeeding indicator was calculated according to the following WHO equation [4];

$$
\begin{aligned}
\text { EIBF }= & \text { (children born in the last } 24 \text { month who } \\
& \text { were put to breast within one } \\
& \text { hour of birth/children born in the last } \\
& 24 \text { months) X } 100
\end{aligned}
$$

The delayed initiation rate of breastfeeding was calculated using the following equation;

$$
\text { Delayed } \operatorname{EIBF}(\%)=100-\% \mathrm{EIBF}
$$

\section{Statistical analysis}

Statistical analyses were done with SPSS software (Statistical Package for Social Sciences; IMB Corp., Armonk, NY, USA), version 21 . The chi-square $\left(X^{2}\right)$ test was used to find the association between categorical groups as a 
preliminary test for regression analysis. Multiple logistic regression was performed to find the possible determinants of delayed early initiation of breastfeeding by the adjusted odds ratio (AOR) and 95\% confidence interval (CI) for different independent variables. To determine the possible factors associated with delaying the early initiation of breastfeeding, two groups were compared: mothers who initiated breastfeeding early $(<1 \mathrm{~h} ; n=\#)$ and mothers who delayed breastfeeding $(>1 \mathrm{~h} ; n=\#)$ in the logistic regression. A $p$ - value of $<0.05$ was considered statistically significant.

Chi-square test $\left(X^{2}\right)$ was used to test the degree of association between the early initiations of breastfeeding (timely vs delayed initiation) against each of selected predictors. These predictors include: methods of delivery (vaginal vs cesarean), location (urban vs rural); receiving of antenatal care and postnatal care, breastfeeding information (yes, no); child order (first vs second and above), mother knowledge about the right time for initiating breastfeeding (yes, no), educational level (secondary and below vs graduates and postgraduates); mother age $(<25$ year vs $\geq 25$ years); occupation (working and students vs housewife), the region of residence (Central, Eastern, Western, Northern and Southern), infant birthweight at delivery ( $<2.5 \mathrm{~kg}$ vs $\geq 2.5 \mathrm{~kg}$ ).

Multiple logistic regression was used to identify the key determinants of early initiation of breastfeeding in the surveyed Saudi mothers. Predictors with chi-square ( $p$ - value of less than 0.05 ) were selected to be included in the multiple logistic regression and then after, running the regression analysis, only the significant predictors were included in the final multiple logistic regression analysis. The dependent variable in the multiple logistic regression was initiation of breastfeeding, which is binominal variable (timely vs delayed). Where "One" was assigned for mothers who initiate breastfeeding within $1 \mathrm{~h}$ of birth and "Zero" otherwise. Multiple logistic regression independent variables include infant method of delivery; mother knowledge about the right time for initiating breastfeeding; education level of the mother; receiving information about breastfeeding and region of residence.

\section{Results}

\section{Demographic characteristics of the study population}

As shown in Table 1 almost half of the mothers (48\%) age was between 20 and 35 years and the other half (50.6\%) were aged 30 years and above. While, $55.8 \%$ of fathers their age was between 30 and 40 years and 19.9\% between 40 to 50 years. Results indicated that the majority of mother (66.5\%) were housewives (unemployed). As for the fathers, the majority of them were working either as government employees (45.8\%) or working in private sector $(36.1 \%)$. It was clear from the collected data that, $49.5 \%$ of mothers and $41.4 \%$ of fathers had university level education. The marital status of the parents showed some differences particularly between divorced mothers (32.1\%) and divorced fathers (18.6\%).

Almost two third of mothers (73.8\%) gave birth naturally (vaginal delivery), while the rest of them (26.2\%) gave birth through caesarean delivery. Regarding the surveyed children, the age distributions of female and male children were more or less equal, 881 (51.8\%) males and $819(48.2 \%)$ females. Table 1 showed that 1190 (70\%) of the children were aged between 7 and 24 months, whereas $510(30 \%)$ of the children were 6 months of age or less. Regarding the age of the previous child, 466 (27.4\%) of children were the first child in the family, whereas 914 (53.7\%) had previous brothers or sisters aged between one and 5 years. Results of the infant's birthweight revealed that,1468 (86.4\%) of the children their birthweights were $2.5 \mathrm{Kg}$ or more, whereas 232 (13.6\%) weighed less than $2.5 \mathrm{Kg}$.

\section{Time of initiation and the early initiation of breastfeeding} According to the WHO, early initiation of breastfeeding (EIBF) indicator is defined as the percentage of children born in the last 24 months who were put to the breast within $1 \mathrm{~h}$ of birth [4]. Out of 1700 infants studied, 1559 (91.7\%) were breastfed and only $8.3 \%$ were never breastfed. Breastfeeding initiation was highest (96.7\%) among mothers in Dammam, the Eastern region and lowest (83\%) was in Hail, the Northern region of KSA. However, Tables 2 and 3 show that 742 (43.6\%) of all infants were breastfed within $1 \mathrm{~h}$ after birth, i.e. had timely initiation of breastfeeding. Though, $457(26.9 \%)$ of all infants were breastfed between 1 and $\leq 24 \mathrm{~h}$ and $360(21.2 \%)$ of them were not breastfed until more than $24 \mathrm{~h}$ after birth. The segregation of data by regions revealed that, Southern regions scored the highest timely initiation (62.7\%) of breastfeeding among the five regions while the Northern region scored the lowest (26.3\%) timely initiation.

The calculated prevalence of the delay in early initiation of breastfeeding showed wide range of variations among the different regions in the Kingdom (Tables 2 and 3). The Western region scored the highest rate (33\%) of delay of initiation of breastfeeding for $24 \mathrm{~h}$ or less. Other regions showed rates of delay of $28.7 \%$ for the Northern; 29\% for the Central; 23\% for the Eastern; and $20 \%$ for the Southern region. As for the extended delay (more than $24 \mathrm{~h}$ ) was reported in Northern region (28\%) followed by the Eastern region (24\%), the Central region $(23 \%)$, the Western region $(17 \%)$ and the Southern region $(12 \%)$ with the overall delay rate of $21 \%$ calculated for all children in the five regions.

Reasons for delaying the early initiation of breastfeeding Table 4 shows the major reasons reported by mothers for delaying the early initiation of breastfeeding for more 
Table 1 Demographic characteristics of the study population

\begin{tabular}{|c|c|c|c|c|c|c|c|c|c|c|c|c|}
\hline \multirow{3}{*}{$\begin{array}{l}\text { Demographic } \\
\text { characteristics }\end{array}$} & \multicolumn{10}{|c|}{ Region } & \multirow{2}{*}{\multicolumn{2}{|c|}{$\begin{array}{l}\text { KSA } \\
n=1700\end{array}$}} \\
\hline & \multicolumn{2}{|c|}{$\begin{array}{l}\text { Central (Riyadh) } \\
n=500\end{array}$} & \multicolumn{2}{|c|}{$\begin{array}{l}\text { Southern (Jazan) } \\
n=300\end{array}$} & \multicolumn{2}{|c|}{$\begin{array}{l}\text { Eastern (Dammam) } \\
n=300\end{array}$} & \multicolumn{2}{|c|}{$\begin{array}{l}\text { Northern (Hail) } \\
n=300\end{array}$} & \multicolumn{2}{|c|}{$\begin{array}{l}\text { Western (Jeddah) } \\
n=300\end{array}$} & & \\
\hline & $\bar{n}$ & $\%$ & $\bar{n}$ & $\%$ & $\bar{n}$ & $\%$ & $\bar{n}$ & $\%$ & $\bar{n}$ & $\%$ & $\bar{n}$ & $\%$ \\
\hline \multicolumn{13}{|l|}{ Maternal age } \\
\hline $15-<20$ years & 7 & 1.4 & 9 & 3.0 & 4 & 1.3 & 2 & 0.7 & 1 & 0.3 & 23 & $1.4 \%$ \\
\hline $20-<25$ years & 86 & 17.2 & 44 & 14.7 & 51 & 17.0 & 28 & 9.3 & 38 & 12.7 & 247 & $14.5 \%$ \\
\hline $25-<30$ years & 189 & 37.8 & 88 & 29.3 & 95 & 31.7 & 107 & 35.7 & 91 & 30.3 & 570 & $33.5 \%$ \\
\hline $30-<35$ years & 103 & 20.6 & 71 & 23.7 & 73 & 24.3 & 85 & 28.3 & 80 & 26.7 & 412 & $24.2 \%$ \\
\hline$\geq 35$ years & 115 & 77.0 & 88 & 29.3 & 77 & 25.7 & 78 & 26.0 & 90 & 30.0 & 448 & $26.4 \%$ \\
\hline \multicolumn{13}{|l|}{ Mother work } \\
\hline Housewife & 368 & 73.6 & 170 & 56.7 & 210 & 70.0 & 200 & 66.7 & 182 & 60.7 & 1130 & $66.5 \%$ \\
\hline Working Mothers & 108 & $21.6 \%$ & 106 & $35.3 \%$ & 83 & $27.7 \%$ & 88 & $29.3 \%$ & 105 & $35 \%$ & 490 & $28.8 \%$ \\
\hline Student & 24 & 4.8 & 24 & 8.0 & 7 & 2.3 & 12 & 4.0 & 13 & 4.3 & 80 & $4.7 \%$ \\
\hline \multicolumn{13}{|l|}{ Mother education } \\
\hline Illiterate & 22 & 4.4 & 12 & 4.0 & 15 & 5.0 & 7 & 2.3 & 10 & 3.3 & 66 & $3.9 \%$ \\
\hline Primary level & 69 & 13.8 & 27 & 9.0 & 12 & 4.0 & 15 & 5.0 & 19 & 6.3 & 142 & $8.4 \%$ \\
\hline Intermediate level & 77 & 15.4 & 34 & 11.3 & 29 & 9.7 & 17 & 5.7 & 31 & 10.3 & 188 & $11.1 \%$ \\
\hline Secondary level & 119 & 23.8 & 69 & 23.0 & 106 & 35.3 & 91 & 30.3 & 76 & 25.3 & 461 & $27.1 \%$ \\
\hline University level & 211 & 42.2 & 158 & 52.7 & 138 & 46.0 & 170 & 56.7 & 164 & 54.7 & 841 & $49.5 \%$ \\
\hline Postgrad level & 2 & 0.4 & 0 & 0.0 & 0 & 0.0 & 0 & 0.0 & 0 & 0.0 & 2 & $0.1 \%$ \\
\hline \multicolumn{13}{|l|}{ Mother marital status } \\
\hline Married & 450 & 90.0 & 293 & 97.7 & 294 & 98.0 & 295 & 98.3 & 287 & 95.7 & 1619 & 61.6 \\
\hline Divorced & 48 & 9.6 & 6 & 2.0 & 6 & 2.0 & 5 & 1.7 & 13 & 4.3 & 78 & 32.1 \\
\hline Widowed & 2 & 0.4 & 1 & 0.3 & 0 & 0.0 & 0 & 0.0 & 0 & 0.0 & 3 & 0.2 \\
\hline \multicolumn{13}{|l|}{ Father age } \\
\hline $20-<30$ years & 108 & 21.6 & 60 & 20.0 & 67 & 22.3 & 46 & 15.3 & 49 & 16.3 & 330 & 19.4 \\
\hline $30-<40$ years & 273 & 54.6 & 159 & 53.0 & 159 & 53.0 & 185 & 61.7 & 172 & 57.3 & 948 & 55.8 \\
\hline $40-<50$ years & 94 & 18.8 & 62 & 20.7 & 62 & 20.7 & 57 & 19.0 & 63 & 21.0 & 338 & 19.9 \\
\hline $50-<60$ years & 23 & 4.6 & 15 & 5.0 & 7 & 2.3 & 10 & 3.3 & 16 & 5.3 & 71 & 4.2 \\
\hline$>60$ years & 2 & 0.4 & 4 & 1.3 & 5 & 1.7 & 2 & 0.7 & 0 & 0.0 & 13 & 0.8 \\
\hline
\end{tabular}

Mother marital status

\begin{tabular}{|c|c|c|c|c|c|c|c|c|c|c|c|c|}
\hline Married & 450 & 90.0 & 293 & 97.7 & 294 & 98.0 & 295 & 98.3 & 287 & 95.7 & 1619 & 61.6 \\
\hline Divorced & 48 & 9.6 & 6 & 2.0 & 6 & 2.0 & 5 & 1.7 & 13 & 4.3 & 78 & 32.1 \\
\hline Widowed & 2 & 0.4 & 1 & 0.3 & 0 & 0.0 & 0 & 0.0 & 0 & 0.0 & 3 & 0.2 \\
\hline
\end{tabular}

Father age

\begin{tabular}{|c|c|c|c|c|c|c|c|c|c|c|c|}
\hline $20-<30$ years & 108 & 21.6 & 60 & 20.0 & 67 & 22.3 & 46 & 15.3 & 49 & 16.3 & 330 \\
\hline $30-<40$ years & 273 & 54.6 & 159 & 53.0 & 159 & 53.0 & 185 & 61.7 & 172 & 57.3 & 948 \\
\hline $40-<50$ years & 94 & 18.8 & 62 & 20.7 & 62 & 20.7 & 57 & 19.0 & 63 & 21.0 & 338 \\
\hline $50-<60$ years & 23 & 4.6 & 15 & 5.0 & 7 & 2.3 & 10 & 3.3 & 16 & 5.3 & 71 \\
\hline$>60$ years & 2 & 0.4 & 4 & 1.3 & 5 & 1.7 & 2 & 0.7 & 0 & 0.0 & 13 \\
\hline
\end{tabular}

Father work

Government employee

Private sector employee

$244 \quad 588$

Private business

$97 \quad 19.4$

$141 \quad 47$

$117 \quad 39.1$

$173 \quad 67.7$

67.7

104

34.7

$\begin{array}{lll}112 & 37.3 & 145\end{array}$

48.3

$779 \quad 45.8$

Father education

$\begin{array}{llllll}159 & 31.8 & 28 & 9.3 & 55 & 18.3\end{array}$

$15 \quad 5.0 \quad 51$

17.0

$613 \quad 36.1$

Illiterate

Primary level

$6 \quad 1.2$

$3-1.0$

Intermediate level

Secondary level

$\begin{array}{llll}52 & 10.4 & 24 & 8.0\end{array}$

University level

$\begin{array}{ll}76 & 15.2 \\ 173 & 34.6\end{array}$

Postgrad level

39
115

$$
13.0
$$

$188 \quad 37.6$

115

38.3

$5 \quad 1.0$

$$
4
$$

38.3

0.67

$\begin{array}{lllll}496 & 99.2 & 295 & 98.3 & 298 \\ 4 & 0.8 & 5 & 1.7 & 2\end{array}$

0.7

$300 \quad 100.0$

$\begin{array}{lll}0.0 & 0.0 \quad 5\end{array}$

98.3
1.7

$1384 \quad 81.4$

Divorced

$$
4
$$

0.8 
Table 1 Demographic characteristics of the study population (Continued)

\begin{tabular}{|c|c|c|c|c|c|c|c|c|c|c|c|c|}
\hline \multirow{3}{*}{$\begin{array}{l}\text { Demographic } \\
\text { characteristics }\end{array}$} & \multicolumn{10}{|c|}{ Region } & \multirow{2}{*}{\multicolumn{2}{|c|}{$\begin{array}{l}\text { KSA } \\
n=1700\end{array}$}} \\
\hline & \multicolumn{2}{|c|}{$\begin{array}{l}\text { Central (Riyadh) } \\
n=500\end{array}$} & \multicolumn{2}{|c|}{$\begin{array}{l}\text { Southern (Jazan) } \\
n=300\end{array}$} & \multicolumn{2}{|c|}{$\begin{array}{l}\text { Eastern (Dammam) } \\
n=300\end{array}$} & \multicolumn{2}{|c|}{$\begin{array}{l}\text { Northern (Hail) } \\
n=300\end{array}$} & \multicolumn{2}{|c|}{$\begin{array}{l}\text { Western (Jeddah) } \\
n=300\end{array}$} & & \\
\hline & $n$ & $\%$ & $n$ & $\%$ & $n$ & $\%$ & $n$ & $\%$ & $n$ & $\%$ & $n$ & $\%$ \\
\hline \multicolumn{13}{|l|}{ Child sex } \\
\hline Male & 229 & 45.8 & 166 & 55.3 & 169 & 56.3 & 160 & 53.3 & 157 & 52.3 & 881 & 51.8 \\
\hline Female & 271 & 54.2 & 134 & 44.7 & 131 & 43.7 & 140 & 46.7 & 143 & 47.7 & 819 & 48.2 \\
\hline \multicolumn{13}{|l|}{ Child age } \\
\hline $1-2$ months & 18 & 3.6 & 30 & 10 & 18 & 6 & 14 & 4.7 & 18 & 6 & 98 & 5.8 \\
\hline 3-4 months & 38 & 7.6 & 29 & 9.7 & 38 & 12.7 & 151 & 50.3 & 46 & 15,3 & 302 & 17.8 \\
\hline $5-6$ months & 47 & 9.4 & 17 & 5.7 & 8 & 2.7 & 0.0 & 0.0 & 38 & 12.7 & 110 & 6.5 \\
\hline 7-12 months & 158 & 31.6 & 87 & 29 & 91 & 30.3 & 2 & 0.7 & 95 & 31.7 & 433 & 25.5 \\
\hline $13-18$ months & 128 & 25.6 & 88 & 29.3 & 67 & 22.3 & 79 & 26.3 & 62 & 20.7 & 424 & 24.9 \\
\hline 19-24 months & 111 & 22.2 & 49 & 16.3 & 78 & 26 & 54 & 18 & 41 & 13.7 & 333 & 19.6 \\
\hline \multicolumn{13}{|l|}{ Method of delivery } \\
\hline Vaginal & 366 & 73.2 & 235 & 78.3 & 241 & 80.3 & 210 & 70.0 & 202 & 67.3 & 1254 & 73.8 \\
\hline Caesarean & 134 & 26.8 & 65 & 21.7 & 59 & 19.7 & 90 & 30.0 & 98 & 32.7 & 446 & 26.2 \\
\hline \multicolumn{13}{|c|}{ Child weight at delivery time } \\
\hline$<2.5 \mathrm{Kg}$ & 106 & 21.2 & 31 & 10.3 & 35 & 11.7 & 30 & 10.0 & 30 & 10.0 & 232 & 13.6 \\
\hline $2.5 \mathrm{Kg}$. & 122 & 24.4 & 118 & 39.3 & 107 & 35.7 & 112 & 37.3 & 122 & 40.7 & 581 & 34.2 \\
\hline$>2.5 \mathrm{Kg}$ & 272 & 54.4 & 151 & 50.3 & 158 & 52.7 & 158 & 52.7 & 148 & 49.3 & 887 & 52.2 \\
\hline \multicolumn{13}{|c|}{ Age of the previous child } \\
\hline $1-2$ years & 27 & 5.4 & 38 & 12.7 & 19 & 6.3 & 43 & 14.3 & 28 & 9.3 & 155 & 9.1 \\
\hline $3-5$ years & 195 & 39.0 & 130 & 43.3 & 122 & 40.7 & 164 & 54.7 & 148 & 49.3 & 759 & 44.6 \\
\hline$>5$ years & 118 & 23.6 & 49 & 16.3 & 56 & 18.7 & 56 & 18.7 & 41 & 13.7 & 320 & 18.8 \\
\hline No previous child & 160 & 32.0 & 83 & 27.7 & 103 & 34.3 & 37 & 12.3 & 83 & 27.7 & 466 & 27.4 \\
\hline
\end{tabular}

than $1 \mathrm{~h}$ after birth. Results showed that the routine practices in the hospitals of separating the newborn from mother immediately after birth, was the main reason (41\%) for the delaying of early initiation of breastfeeding, as stated by the mothers. This was typical in all regions but higher (49 and 44\%) in the Northern and Western regions respectively compared to $35-37 \%$ in the other regions. Caesarean operation was the second higher (25.9\%) reason for the delay of EIBF across the country, however the highest rates were observed in the Western and Southern regions (39 and 27\% respectively). Delay because of the caesarean operation ranged between 20 and $24 \%$ in the other regions. Other reasons for the delay of early initiation of breastfeeding revealed by the study were mother sickness (10.7\%), prelacteal feeding (10.3\%), and child sickness (4.6\%). Also to a lesser extent, lack of breast milk (2.3\%), lack of knowledge about breastfeeding (1.6\%) and cultural factors (1.1\%).

Table 2 Time of initiation of breastfeeding

\begin{tabular}{|c|c|c|c|c|c|c|c|c|}
\hline \multirow[b]{3}{*}{ Region } & \multicolumn{8}{|c|}{ Initiation of breastfeeding EIBF (\%) } \\
\hline & \multicolumn{2}{|c|}{$<1$ Hour (less than $1 \mathrm{~h}$.) } & \multicolumn{2}{|c|}{$1 \leq 24 h$} & \multicolumn{2}{|c|}{$>24$ Hours } & \multicolumn{2}{|c|}{ Never breast fed } \\
\hline & $n$ & $\%$ & $n$ & $\%$ & $n$ & $\%$ & $n$ & $\%$ \\
\hline Northern (Hail): $n=300$ & 79 & 26.3 & 86 & 28.7 & 84 & 28 & 51 & 17 \\
\hline Central (Riyadh): $n=500$ & 192 & 38.4 & 145 & 29 & 115 & 23 & 48 & 9.6 \\
\hline Western (Jeddah): $n=300$ & 135 & 45.0 & 98 & 33 & 52 & 17 & 15 & 5 \\
\hline Eastern (Dammam): $n=300$ & 148 & 49.3 & 69 & 23 & 73 & 24.3 & 10 & 3.3 \\
\hline Southern (Jazan): $n=300$ & 188 & 62.7 & 59 & 20 & 36 & 12 & 17 & 6 \\
\hline Total (KSA): $n=1700$ & 742 & 43.6 & 457 & 26.9 & 360 & 21.2 & 141 & 8.3 \\
\hline
\end{tabular}


Table 3 Timely/early initiation and delayed initiation of breastfeeding

\begin{tabular}{lllllll}
\hline & \multicolumn{2}{c}{ Timely initiation } & & Delayed initiation & $p$-value \\
\cline { 2 - 3 } & $n$ & $\%$ & & $n$ & $\%$ & \\
\hline Central (Riyadh) & 192 & 38.4 & & 308 & 61.6 & $90.44(<0.001)$ \\
Northern (Hail) & 79 & 26.3 & & 221 & 73.7 & \\
Eastern (Damam) & 148 & 49.3 & & 152 & 50.7 & \\
Western (Jeddah) & 135 & 45 & & 165 & 55 & \\
Southern (Jazan) & 188 & 62.7 & & 112 & 37.3 & \\
KSA & 742 & 43.6 & 958 & 56.4 & \\
\hline
\end{tabular}

Cultural practices that involve discarding colostrum, feeding newborns supplemental foods or drinks, having a health professional routinely give the newborn a specific liquid such as sugar water or infant formula, were all investigated among the mothers. Results (Table 5) indicated that only $47 \%$ of the newborn babies have been fed colostrum. Colostrum feeding was highest (65\%) among newborns of the Southern region and lowest (25\%) in the Northern region. More importantly, $51 \%$ of the newborn babies were found to be fed infant formula as the first feed. This practice was mainly performed by health personnel with the hospital delivery.

\section{Determinants of the early initiation of breastfeeding in KSA}

A significant difference was observed in early initiation of breastfeeding between mothers who delivered vaginally $633(85 \%)$ and those delivered by caesarean section 109 (15\%), between mothers who knew about the right time for early initiation of breastfeeding 630 (85\%) and those who didn't know 112 (15\%), between mothers who received information about breastfeeding 524 (71\%) and those who didn't receive any breastfeeding information 218 (29\%), and finally, between mothers who were resident of the different regions of the kingdom $(38,26,61$,
45 and 63\%) for the Central, Northern, Eastern, Western and the Southern regions respectively (Table 6).

On the other hand, five variables showed no significant difference (Table 6) in practicing initiation of breastfeeding (timely vs delayed). These variables were: infant birthweight $(<2.5 \mathrm{~kg}$ vs $\geq 2.5 \mathrm{~kg})$, antenatal and postnatal care, mother age ( $<25$ years vs $\geq 25$ years), mother work (working mothers and student vs housewives) and residence location (urban vs rural).

Additionally, multivariable logistic regression, was performed to assess determinants related to early initiation of breastfeeding (Table 7). It is clearly evident that, early initiation of breastfeeding was significantly associated with the mode of delivery (vaginal vs caesarean) (AOR 2.071; 95\% CL 1.43, 2.99) i.e. mothers who had a caesarean delivery had about 2.07 times higher odds for delaying breastfeeding by $>1 \mathrm{~h}$ when compared to mothers who had a vaginal delivery. Moreover, significant association was also observed between early initiation of breastfeeding and mother educational level (AOR 1.54; 95\% CL 1.13, 2.11); uninformed mothers regarding the right time for the early initiation of breastfeeding (AOR 0.012 ; $95 \%$ CI $0.0028,0.017$ ) and mothers who received breastfeeding information during pregnancy (AOR 1.49; 95\% CI 1.026, 2.54).

\section{Discussion}

General characteristics of the study participants such as age distributions of female and male children (52/48\%), multiparity (73\%), vaginal as a common mode of delivery (73.8\%), and a normal birthweight (86.4\%) were similar to the results of the Saudi population (2016) reported by the General Authority of Statistics of KSA [2].

In this study only $8.3 \%$ of mothers did not initiate breastfeeding, this is nearly similar to $8.1 \%$ rate reported by El Gilany [27], however earlier studies in KSA reported rates of never breastfeeding ranged

Table 4 Reasons reported by mothers for delaying the initiation of breastfeeding

\begin{tabular}{|c|c|c|c|c|c|c|c|c|c|c|c|c|}
\hline \multirow[t]{2}{*}{ Reasons } & \multicolumn{2}{|c|}{$\begin{array}{l}\text { Central (Riyadh): } \\
n=500\end{array}$} & \multicolumn{2}{|c|}{$\begin{array}{l}\text { Eastern (Dammam): } \\
n=300\end{array}$} & \multicolumn{2}{|c|}{$\begin{array}{l}\text { Northern (Hail): } \\
n=300\end{array}$} & \multicolumn{2}{|c|}{$\begin{array}{l}\text { Western (Jeddah): } \\
n=300\end{array}$} & \multicolumn{2}{|c|}{$\begin{array}{l}\text { Southern (Jazan): } \\
n=300\end{array}$} & \multicolumn{2}{|c|}{$\begin{array}{l}\text { KSA: } \\
n=1700\end{array}$} \\
\hline & $\bar{n}$ & $\%$ & $\bar{n}$ & $\%$ & $\bar{n}$ & $\%$ & $\bar{n}$ & $\%$ & $\bar{n}$ & $\%$ & $\bar{n}$ & $\%$ \\
\hline Delay at the place of delivery & 114 & 37 & 72 & 36 & 130 & 49 & 82 & 44 & 44 & 35 & 442 & 40.9 \\
\hline Caesarean delivery & 74 & 24 & 39 & 20 & 60 & 23 & 73 & 39 & 34 & 27 & 280 & 25.9 \\
\hline Mother sickness & 38 & 12 & 23 & 12 & 31 & 12 & 10 & 5 & 14 & 11 & 116 & 10.7 \\
\hline Child given prelacteal feed & 4 & 1 & 39 & 20 & 30 & 11 & 15 & 8 & 23 & 18 & 111 & 10.3 \\
\hline Cultural factors & 6 & 2 & 4 & 2 & 2 & 1 & 0 & 0 & 0 & 0 & 12 & 1.1 \\
\hline Child sickness & 29 & 9 & 10 & 5 & 4 & 2 & 3 & 2 & 4 & 3 & 50 & 4.6 \\
\hline No reasons & 28 & 9 & 0 & 0 & 0 & 0 & 0 & 0 & 0 & 0 & 28 & 2.6 \\
\hline Lack of breast milk & 8 & 3 & 8 & 4 & 5 & 2 & 2 & 1 & 2 & 2 & 25 & 2.3 \\
\hline Lack of knowledge of breastfeeding & 7 & 2 & 3 & 2 & 1 & 0.4 & 1 & 0.5 & 5 & 4 & 17 & 1.6 \\
\hline Total & 308 & 100 & 198 & 100 & 263 & 100 & 186 & 100 & 126 & 100 & 1081 & 100 \\
\hline
\end{tabular}


Table 5 Newborn first feed

\begin{tabular}{|c|c|c|c|c|c|c|c|}
\hline \multirow[t]{3}{*}{ Region } & \multicolumn{6}{|c|}{ Newborn first feed } & \multirow{3}{*}{$\begin{array}{l}\text { Chi-square } \\
\text { ( } p \text { - value) }\end{array}$} \\
\hline & \multicolumn{2}{|c|}{ Breast milk } & \multicolumn{2}{|c|}{ Infant formula } & \multicolumn{2}{|c|}{ Glucose water } & \\
\hline & $n$ & $\%$ & $n$ & $\%$ & $n$ & $\%$ & \\
\hline Central (Riyadh) & 174 & 38.4 & 320 & 64 & 6 & 1.2 & $167(<0.001)$ \\
\hline Northern (Hail) & 75 & 25 & 215 & 71.3 & 10 & 33 & \\
\hline Eastern (Dammam) & 177 & 59 & 120 & 40 & 3 & 1 & \\
\hline Western (Jeddah) & 172 & 57.3 & 120 & 40 & 8 & 2.3 & \\
\hline Southern (Jazan) & 196 & 65.3 & 97 & 32.3 & 7 & 2.3 & \\
\hline KSA & 794 & 46.7 & 872 & 51.3 & 34 & 2 & \\
\hline
\end{tabular}

from 1.4 to $13.1 \%[21,25,30-33]$. The high prevalence of breastfeeding initiation observed in the current study (91.7\%) denotes the inclination of Saudi mothers to breastfed, a fact that was also reached by other investigators [3, 26, 27, 34, 35]. Previous studies showed similar initiation rates of $95 \%$ in Riyadh [23], $80.2 \%$ in Mecca [28], $90 \%$ in Western region [35], 91.9\% in Al-Hassa (Eastern region) [27] and $87.7 \%$ in Central region $[23,36]$. The prevalence of breastfeeding initiation showed variation between the different region of the country where, Eastern, Western and Southern regions reported the highest initiation rates of 96.7, 95 and 94\% respectively, and 90\% for the Central region, while the Northern region reported the lowest $(83 \%)$ initiation rates. Similar results were obtained by Al-Hreashy et al. [36].

Despite the high breastfeeding initiation rate of $91.7 \%$, the early initiation of breastfeeding (within $1 \mathrm{~h}$ after birth) for the country (44\%), considered as a "fair" score according to the WHO criteria. The sub-regional data showed variations from a "good score" of $63 \%$ in the Southern region, followed by "fair scores" of 49.3, 45 and $38.4 \%$ in each of the Eastern, Western and Central regions respectively. While, the lowest "poor score" of $26.3 \%$ was reported in the Northern region. This rate of $44 \%$ EIBS is higher than the 11.4 and $23.2 \%$ obtained by El-Gilany et al. [27] and Al-Mouzan et al. [25] respectively, though, it is similar to the EIBF rates reported by UNICEF [37] in Pakistan, India, Bangladesh and Nepal (29, 41, 47 and 45\% respectively). Moreover, this result of $44 \%$ is not far from the $38.1 \%$ result obtained by Azzeh et al. in Mecca region [28] and the 51.3\% reported by Alwelaie in Riyadh [23]. In contrast a low EIBF rate of $16.7 \%$ was reported by Albokhary in Jeddah, [38], 22\% reported in Taif [39, 40] and 21.6\% reported by Al-Hreashy in Dammam [36].

The overall delay in EIBF of 27 and 21\% for less than $24 \mathrm{~h}$. and that beyond $24 \mathrm{~h}$. respectively, were similar to the results (28.1\%) obtained by El Mouzan et al. [25] for delayed initiation of beyond the first $6 \mathrm{hrs}$. of birth. However, Azzeh et al. [28], reported 42.7\% delay in the initiation of breastfeeding beyond $1 \mathrm{~h}$ after birth in Western region of KSA.

Factors associated with the compliance with the EIBF ( $\leq 1 \mathrm{~h}$. after birth) found in the present study were the mode of delivery (50\% for natural vs $24 \%$ caesarean delivery), residential location (46\% for rural vs $43 \%$ urban residence), child birthweight (31\% for low birthweight children, 49\% for normal birthweight children and 43\% for children with birthweight $\geq 2.5 \mathrm{Kg}$.), and child order ( $39 \%$ one child vs $46 \%$ the second child and more).

The significant effect of caesarean section was indicated by the high delay rate in EIBF among KSA mothers in the present study. Results of the effect of caesarean section were consistent with those obtained by Azzeh et al. [28], in Mecca, and that obtained by Alzaheb in Tabuk region in KSA [8] and with other previous studies in KSA [38, 40], which recognized caesarean section as a risk factor for delaying breastfeeding initiation.

In consistent with results obtained by Gilany [27], this study revealed that mothers with higher parity (46\%) were more likely to initiate breastfeeding within the first hour of birth. However, and contradicting to Badaya et al. and Mathur et.al [41, 42], results of this study revealed that, rates of timely initiation of breastfeeding is higher (49\%) among children with low birthweight $(<2.5 \mathrm{Kg}$.),

The main reported reason for delaying early initiation of breastfeeding beyond $1 \mathrm{~h}$ of birth was the delay from the place of delivery (40.9\%) i.e. mothers and babies were separated immediately after birth and the newborn brought back to mother after more than $1 \mathrm{~h}$ after delivery. Similar findings were reported in KSA by Ogbeide et al. [6], Mosher [43], Azzeh et al. [28], Fida [35] and in Greece by Daglas et al. [42] and Mathur et al. [44] in India.

This delay highlights practices at the place of delivery, and raises the issue of suitable hospital policies and staff training be implemented to support mothers in timely initiating breastfeeding, and to discourage free distribution of breast milk substitutes in hospital, all have a significant relationship with early initiation of breastfeeding $[8,23,45,46]$. In this study, giving prelacteal feed was reported by $10.3 \%$ of mothers as a reason for delaying 
Table 6 Determinants of timely initiation of breastfeeding: degree of association

\begin{tabular}{|c|c|c|c|}
\hline \multirow[t]{2}{*}{ Parameter } & \multicolumn{2}{|c|}{ Early initiation of breastfeeding $(n=1700)$} & \multirow{2}{*}{$\begin{array}{l}p-\text { value } \\
\text { (Chi-square) }\end{array}$} \\
\hline & Delayed initiation & Timely initiated & \\
\hline \multicolumn{4}{|l|}{ Location } \\
\hline Urban & $776(45.7 \%)$ & $584(34.4 \%)$ & \multirow[t]{2}{*}{$1.378(0.241)$} \\
\hline Rural & $182(10.7 \%)$ & $158(9.3 \%)$ & \\
\hline \multicolumn{4}{|l|}{ Method of delivery } \\
\hline vaginal & $621(36.5 \%)$ & $633(37.2 \%)$ & \multirow[t]{2}{*}{$90.6(0.001)$} \\
\hline Caesarean & 337 (19.8\%\%) & $109(6.4 \%)$ & \\
\hline \multicolumn{4}{|l|}{ Received antenatal care } \\
\hline Yes & $886(52.1 \%)$ & $693(40.8 \%)$ & \multirow[t]{2}{*}{$0.526(0.468)$} \\
\hline No & $72(4.2 \%)$ & $49(2.9 \%)$ & \\
\hline \multicolumn{4}{|l|}{ Received postnatal care } \\
\hline Yes & $823(48.4 \%)$ & $636(37.4 \%)$ & \multirow[t]{2}{*}{$0.013(0.91)$} \\
\hline No & $135(7.9 \%)$ & $106(6.2 \%)$ & \\
\hline \multicolumn{4}{|l|}{ Previous child (child order) } \\
\hline No previous child & $286(16.8 \%)$ & $180(10.6 \%)$ & \multirow[t]{2}{*}{$6.58(0.01)$} \\
\hline Second child and above & $672(39.5 \%)$ & $562(33.1 \%)$ & \\
\hline \multicolumn{4}{|c|}{ Knowledge about timing of breastfeeding initiation } \\
\hline Don't know when to initiate breastfeeding & $884(52 \%)$ & $112(6.6 \%)$ & \multirow[t]{2}{*}{$1026.6(<0.001)$} \\
\hline Know when to initiate breastfeeding & $74(4.4 \%)$ & $630(37.1 \%)$ & \\
\hline \multicolumn{4}{|l|}{ Infant's mother educational level } \\
\hline Secondary school level and below & $456(26.8 \%)$ & $400(23.5 \%)$ & \multirow[t]{2}{*}{$6.65(0.01)$} \\
\hline Graduate and postgraduate levels & $502(29.5 \%)$ & $342(20.1 \%)$ & \\
\hline \multicolumn{4}{|l|}{ Child mother age } \\
\hline$<25$ year & $146(8.6 \%)$ & $124(\%) 7.3$ & \multirow[t]{2}{*}{$0.678(0.41)$} \\
\hline$\geq 25$ years & $812(47.8 \%)$ & $618(36.4 \%)$ & \\
\hline \multicolumn{4}{|l|}{ Child weight at delivery time } \\
\hline$<2.5 \mathrm{Kg}$ & $161(9.5 \%)$ & $71(4.2 \%)$ & \multirow[t]{2}{*}{$18.58(<0.001)$} \\
\hline$\geq 2.5 \mathrm{Kg}$ & 797 (46.9\%) & $671(39.5 \%)$ & \\
\hline \multicolumn{4}{|l|}{ Receiving breastfeeding information } \\
\hline Yes & $551(32.4 \%)$ & $524(30.8 \%)$ & \multirow[t]{2}{*}{$30.8(<0.001)$} \\
\hline No & 407 (23.9\%) & $218(12.8 \%)$ & \\
\hline \multicolumn{4}{|l|}{ Child mother occupation } \\
\hline Working woman & $340(20 \%)$ & $230(13.5 \%)$ & \multirow[t]{2}{*}{$3.79(0.052)$} \\
\hline Housewife & $618(36.4 \%)$ & $512(30.1 \%)$ & \\
\hline \multicolumn{4}{|l|}{ Region } \\
\hline Central (Riyadh) & $308(18.1 \%)$ & $192(11.3 \%)$ & \multirow[t]{5}{*}{$90.45(<0.001)$} \\
\hline Northern (Hail) & $221(13 \%)$ & $79(4.7 \%)$ & \\
\hline Eastern (Dammam) & $152(8.9 \%)$ & 148 (8.7\%) & \\
\hline Western (Jeddah) & $165(9.7 \%)$ & $135(7.9 \%)$ & \\
\hline Southern (Jazan) & $112(6.6 \%)$ & $188(11.1 \%)$ & \\
\hline
\end{tabular}

the early initiation of breastfeeding. This is similar previous studies $[8,27,47,48]$ who also suggested that prelacteal feeding may result in lactation failure [27] and weakens the infant suckling stimulus [48].
The high consumption of infant formula among > 50\% of mothers reported in this study could be related to breastfeeding practices in KSA such as, the low rate (less than $10 \%$ ) of exclusive breastfeeding up to 6 months of 
Table 7 Multivariable logistic regression parameter estimates of early initiation of breastfeeding

\begin{tabular}{|c|c|c|}
\hline Parameter & B & Adjusted Odds Ratio (95\% Confidence Interval) \\
\hline \multicolumn{3}{|l|}{ Method of delivery } \\
\hline Vaginal & $0.728^{\mathrm{a}}(0.188)$ & $2.071(1.43,2.99)$ \\
\hline Caesarean & 0 & 1 \\
\hline \multicolumn{3}{|c|}{ Knowledge about timing of breastfeeding initiation } \\
\hline Don't know when to initiate breastfeeding & $-4.442^{\mathrm{a}}(0.191)$ & $0.012(0.008,0.017)$ \\
\hline Know when to initiate breastfeeding & 0 & 1 \\
\hline \multicolumn{3}{|l|}{ Maternal educational level } \\
\hline Secondary school level and below & $0.432^{\mathrm{a}}(0.161)$ & $1.541(1.13,2.11)$ \\
\hline Graduate and postgraduate levels & 0 & 1 \\
\hline \multicolumn{3}{|l|}{ Breastfeeding information } \\
\hline Yes & $0.397^{\mathrm{a}}(0.189)$ & $1.487(1.026,2.54)$ \\
\hline No & 0 & 1 \\
\hline \multicolumn{3}{|l|}{ Region } \\
\hline Middle & $0.944^{\mathrm{a}}(0.259)$ & $2.57(1.55,4.27)$ \\
\hline Northern & $0.621^{a}(0.292)$ & $1.86(1.05,3.297)$ \\
\hline Eastern & $0.705^{\mathrm{a}}(0.276$ & $2.03(1.18,3.45)$ \\
\hline Western & $0.891^{\mathrm{a}}(0.78)$ & $2.437(1.41,4.12)$ \\
\hline Southern & 0 & 1 \\
\hline
\end{tabular}

${ }^{a}$ significant at $5 \%$ level of significance or less

age $[19,24-26]$, and the partial breastfeeding that became a trend for feeding in the country $[25,26,36]$. In addition to the non-compliance with the International Code of Marketing Breast Milk Substitutes [19, 25, 28], and the lack of strict monitoring system for registration and marketing of infant formulas from the Saudi authorities [39, 43].

\section{Determinants of the early initiation of breastfeeding in KSA}

The results of the chi-square test $(p-$ value of $<0.05)$ and the multivariant analysis indicated that women who gave birth vaginally were more likely to timely initiate breastfeeding than those who had a caesarean section (AOR 2.071; 95\% CL 1.43, 2.99). These results are consistent with previous studies in KSA [34, 35, 39, 40], which identified caesarean section as a risk factor for breastfeeding initiation. This study has identified another four factors as having statistically significant associations with early initiation of breastfeeding. The first positively associated factor is the knowledge of the mother about the right time for early initiation (AOR $0.012 ; 95 \%$ CI $0.0028,0.017$ ). The other significantly associated factors with the early initiation, were receipt of breastfeeding information during pregnancy (AOR 1.49; 95\% CI 1.026, 2.54), educational level of the mother (AOR 1.54; 95\% CL 1.13, 2.11) and finally, the region of residence (Central, Northern, Southern, Eastern and Western).

\section{Conclusions}

The main determinant of the early initiation of breastfeeding were the infants' mothers: who give birth by caesarean section, educational level (graduates and above); who didn't receive breastfeeding information; unknowledgeable about the right time of breast feeding as well as the residence region.

The key finding of this study is that the initiation of breastfeeding is high while, the early or timely breastfeeding initiation (within $1 \mathrm{~h}$ of birth) is considered fair according to the World Health Organization classification. However, the willingness of Saudi mothers to breastfeed indicated by the high prevalence of breastfeeding initiation, must be supported by effective government policy regarding breastfeeding support and marketing of breast milk substitutes. Moreover, behavior change strategies, are needed to encourage mothers and families to demand support for the early initiation of breastfeeding from health personnel. Nonetheless, links between health facilities and communities need to be strengthened, and community networks that protect, promote and support breastfeeding should be encouraged.

\section{Abbreviations}

AOR: Adjusted Odd Ratio; EIBF: Early initiation of breastfeeding;

EMRO: Eastern Mediterranean Regional Office; FMOH: Federal Ministry of health; IRB: Institutional review board; IYCF: Infant and young child feeding; KACST: King Abdul-Aziz city for science and technology; KSA: Kingdom of Saudi Arabia; KSU: King Saud University; MENA: Middle East and North Africa; MOH: Ministry of health; NSTIP: National science, technology and innovation 
plan; PHCCs: Primary health care centers; UNICEF: United Nations Children's Fund; WBTi: World Breastfeeding Trend initiative; WHO: World Health Organization

\section{Acknowledgements}

We thank all the women who participated in this study and all the nurses and physicians at the primary health care centers, who were of great help in this work.

\section{Funding}

This Project was funded by the National Plan for Science, Technology and Innovation King Abdul-Aziz City for Science and Technology, Kingdom of Saudi Arabia, Award Number (11-MED1867-02).

\section{Availability of data and materials}

Please contact author for data requests.

\section{Authors' contributions}

AA Conceived the study, coordinated data collection, performed the statistical analysis, and drafted the manuscript. OS participated in the coordination of the data collection and edited the final draft of the manuscript. All authors read and approved the final manuscript.

\section{Ethics approval and consent to participate}

The Institutional Review Board (IRB) of King Saud University (KSU) has ethically approved the study with reference number E-14-1101. Written informed consents were obtained from all participants and confidentiality was assured. Participants have the right to withdraw, without any consequence, at any time prior to or at any point, during or after the start of the study. Participants were assured that any information provided will be used only for research purposes.

\section{Consent for publication}

Not applicable.

\section{Competing interests}

The authors declare that they have no competing interests.

\section{Publisher's Note}

Springer Nature remains neutral with regard to jurisdictional claims in published maps and institutional affiliations.

\section{Author details}

${ }^{1}$ College of Agriculture and Food Sciences, King Faisal University, Al-Hafouf, Kingdom of Saudi Arabia. ${ }^{2}$ Department of Agribusiness and Consumer Sciences, University of Khartoum, Shambat, Sudan. ${ }^{3}$ Department of Community Health, College of Applied Medical Sciences, King Saud University, Riyadh, Kingdom of Saudi Arabia.

Received: 30 April 2018 Accepted: 20 March 2019

Published online: 02 April 2019

\section{References}

1. United Nations, Department of Economic and Social Affairs, Population Division. World Population Prospects: The Revision, 2017. https://www.un. org/development/desa/publications/world-population-prospects-the-2017revision.html.

2. General Authority for Statistics, Kingdom of Saudi Arabia: Demographic Survey 2016. https://www.stats.gov.sa.

3. The World Breastfeeding Trends Initiative (WBTi). Kingdom of Saudi Arabia report. http://worldbreastfeedingtrends.org/GenerateReports/report/WBTiSaudi-Arabia-2016.pdf

4. World Health Organization (WHO). Indicators for assessing infant and young child feeding practices. Part I: definitions. Conclusions of a consensus meeting held 6-8. November 2007 in Washington D.C., USA. Geneva: WHO; 2008.

5. United Nations Children's Fund (UNICEF). World Health Organization. Capture the moment, early initiation of breastfeeding: The best start for every newborn. New York: UNICEF; 2018.

6. Ogbeide DO, Siddiqui S, Al Khalifa IM, Karim A. Breast feeding in a Saudi Arabian community. Profile of parents and influencing factors. Saudi Med J. 2004;25(5):580-4.
7. Al-Jawaldeh A, Abul-Fadl A. Assessment of the baby friendly hospital initiative implementation in the eastern Mediterranean region. Children. 2018;5(3):41.

8. Alzaheb R. A review of the factors associated with the timely initiation of breastfeeding and exclusive breastfeeding in the Middle East. Clin Med Insights: Pediatr. 2017;11:1-15.

9. Ip S, Chung M, Raman G, Trikalinos T, Lau J. A summary of the agency for healthcare research and quality's evidence report on breastfeeding in developed countries. Breastfeed Med. 2009;4(s1):17-30.

10. World Health Organization (WHO). Baby-friendly hospital initiative: revised, updated and expanded for integrated care. Strengthening and sustaining the baby-friendly hospital initiative: a course for decision-makers. Geneva: WHO; 2009. [online] Available at: http://www.who.int/nutrition/publications/ infantfeeding/bfhi_trainingcourse/en/ [Accessed 7 Dec 2018]

11. United Nations Children's Fund (UNICEF) and the World Health organization (WHO). Country experiences with the Baby-friendly Hospital Initiative: Compendium of case studies of the Baby-friendly Hospital Initiative. New York: UNICEF, Nutrition Section; 2017. [Online] Available at: https://www. unicef.org/nutrition/files/BFH__Case_Studies_FINAL.pdf.

12. Victora CG, Bahl R, Barros AJ, GVA F, Horton S, Krasevec J, et al. Breastfeeding in the 21st century: epidemiology, mechanisms, and lifelong effect. Lancet. 2016;387(10017):475-90.

13. Smith ER, Hurt L, Chowdhury R, Sinha B, Fawzi W, Edmond KM. Delayed breastfeeding initiation and infant survival: a systematic review and metaanalysis. PLoSOne. 2017;12(7):e0180722.

14. Khan J, Vesel $L$, Bahl R, Martines JC. Timing of breastfeeding initiation and exclusivity of breastfeeding during the first month of life: effects on neonatal mortality and morbidity a systematic review and meta-analysis. Matern Child Health J. 2015;19(3):468-79.

15. Dubois L, Girard M. Social determinants of initiation, duration and exclusivity of breastfeeding at the population level: the results of the longitudinal study of child development in Quebec (ELDEQ 1998-2002). Can J Public Health. 2003;94(4):300-5.

16. World Health Organization (WHO). Standards for improving quality of maternal and newborn care in health facilities. Geneva; 2016. [online] Available at: https://www.who.int/maternal_child_adolescent/documents/ improving-maternal-newborn-care-quality/en/. Accessed 27 Mar 2019.

17. Perrine CG, Galuska DA, Dohack JL, Shealy KR, Murphy PE, Grummer-Strawn LM, et al. Vital Signs: Improvements in maternity care policies and practices that support breastfeeding. United States, 2007-2013. Morb Mortal Wkly Rep (MMWR). 2015;64(39):1112-7 Report posted as an MMWR early release on the MMWR website (https://www.cdc.gov/mmwr/index.html).

18. Vieira TO, Vieira GO, Giugliani ER, Mendes CM, Martins CC, Silva LR. Determinants of breastfeeding initiation within the first hour of life in a Brazilian population: cross-sectional study. BMC Public Health. 2010;10:760.

19. Alyousefi NA, Alharbi AA, Almugheerah BA, Alajmi NA, Alaiyashi SM, Alharbi SS, et al. Factors influencing Saudi mothers' success in exclusive breastfeeding for the first six months of infant life: a cross-sectional observational study. Int J Med Res Health Sci. 2017;6(2):68-78.

20. Amin T, Hablas H, Al Qader A. Determinants of initiation and exclusivity of breastfeeding in Al Hassa, Saudi Arabia. Breastfeed Med. 2011;6(2):59-68.

21. Al-Jassir M, El-Bashir B, Moizuddin S. Surveillance of infant feeding practices in Riyadh city. Ann Saudi Med. 2004;24(2):136-40.

22. Shawky S, Abalkhail B. Maternal factors associated with the duration of breast feeding in Jeddah, Saudi Arabia. Paediatr Perinat Epidemiol. 2003;17(1):91-6.

23. Alwelaie YA, Alsuhaibani EA, Al-Harthy AM, Radwan RH, Al-Mohammady RG, Almutairi AM, et al. Breastfeeding knowledge and attitude among Saudi women in Central Saudi Arabia. Saudi Med J. 2010;31(2):193-8.

24. Al-Mazrou Y, Aziz K, Khalil M. Breastfeeding and weaning practices in Saudi Arabia. J Trop Pediatr. 1994;40(5):267-71.

25. El Mouzan M, Al Omar A, Al Salloum A, Al Herbish A, Qurachi M. Trends in infant nutrition in Saudi Arabia: compliance with WHO recommendations. Ann Saudi Med. 2009;29(1):20-3.

26. Al Juaid D, Binns C, Giglia R. Breastfeeding in Saudi Arabia: a review. Int Breastfeed J. 2014;9:1.

27. El-Gilany A, Shady E, Helal R. Exclusive breastfeeding in Al-Hassa, Saudi Arabia. Breastfeed Med. 2011;6(4):209-13.

28. Azzeh FS, Alazzeh AY, Hijazi HH, Wazzan HY, Jawharji MT, Jazar AS, et al. Factors associated with not breastfeeding and delaying the early initiation of breastfeeding in Mecca region, Saudi Arabia. Children. 2018;5(1):8.

29. Mack N, Woodsong C, Macqueen K, Guest G, Namey E. Qualitative research methods: A data collector's field guide. North Carolina: Family Health International, FLI USAID; 2005. 
30. Al-Sakeit MA. A study of the factors influencing breastfeeding patterns in Saudi Arabia. Saudi Med J. 1998;9:596-601.

31. Al-Mazrou YY, Farid S. Saudi Arabia child health survey. Riyadh: Ministry of Health; 1991.

32. Madani K, Al-Nowaisser A, Khashoggi R. Breastfeeding patterns in Saudi Arabia. Ecol Food Nutr. 1994;31(3-4):239-45.

33. Khoja T, Farid S. Gulf family health survey. Riyadh: King Fahad National Library for Council of Health Ministers of GCC States; 2000.

34. Alzaheb R. Factors associated with the initiation of breastfeeding within the first 48 hours of life in Tabuk, Saudi Arabia. Int Breastfeed J. 2016;11:21.

35. Fida NM, Al-Aama JY. Pattern of infant feeding at a University Hospital in Western Saudi Arabia. Saudi Med J. 2003;24(7):725-9.

36. Al-Hreashy FA, Tamim HM, Al-Baz N, Al-Kharji NH, Al-Amer A, Al-Ajmi H, et al. Patterns of breastfeeding practice during the first 6 months of life in Saudi Arabia. Saudi Med J. 2008;29(3):427-31.

37. United Nations Children's Fund (UNICEF). State of the World's Children 2014: Every child counts. New York: United Nations Children's Fund (UNICEF); 2014.

38. Albokhary AA, James JP. Does cesarean section have an impact on the successful initiation of breastfeeding in Saudi Arabia? Saudi Med J. 2014 35(11):1400-3.

39. Salih M. Why mothers are not exclusively breast feeding their babies till 6 months of age? Knowledge and practices data from two large cities of the Kingdom of Saudi Arabia. Sudanese J Paediatr. 2018;18(1):28-38.

40. Dorgham LS, Hafez SK, Kamhawy HE, Hassan WB. Assessment of initiation of breastfeeding, prevalence of exclusive breast feeding and their predictors in Taif, KSA. Life Sci J. 2014;11(1):1-9.

41. Badaya N, Jain S, Kumar N. Time of initiation of breastfeeding in various modes of delivery and to observe the effect of low birth weight and period of gestation on initiation of breastfeeding. In J Contemp Pediatr. 2018;5(4): 1509-17.

42. Mathur GP, Pandey PK, Mathur S, Mishra VK, Singh K, Bhatt OP, et al. Breastfeeding status and marketing practices of baby food manufactured in nursing homes. Indian Pediatr. 1993;30(11):1333-5.

43. Mosher C, Sarkar A, Hashem AA, Hamadah RE, Alhoulan A, AlMakadma YA, et al. Self-reported breastfeeding practices and the baby friendly hospital initiative in Riyadh, Saudi Arabia: prospective cohort study. BMJ Open. 2016; 6(12):e012890

44. Daglas M, Petoussi V, Dionysiou G, Athanassakis I. Do maternity hospital practices support Greek mothers' decision to breastfeed? Clin Exp Obstet Gynecol. 2010;37(1):43-8.

45. Piper S, Parks PL. Predicting the duration of lactation: evidence from a national survey. Birth. 2012;23:7-12.

46. Al-Kohii S, Said HA, Selim NA. Breastfeeding practice and determinants among Arab mothers in Qatar. Saudi Med J. 2012;33:436-42.

47. Hossain M, Reves R, Radwan M, Habib M, DuPont H. The timing of breastfeeding initiation and its correlates in a cohort of rural Egyptian infants. J Trop Pediatr. 1995:41(6):354-9.

48. Ebrahim GJ. Social and community paediatrics in developing countries. In. Eastern Mediterranean Health Journal. Edited by El-Gilany A, Sarraf B, AlWehady A, 2012; 18(3): 250.

Ready to submit your research? Choose BMC and benefit from:

- fast, convenient online submission

- thorough peer review by experienced researchers in your field

- rapid publication on acceptance

- support for research data, including large and complex data types

- gold Open Access which fosters wider collaboration and increased citations

- maximum visibility for your research: over $100 \mathrm{M}$ website views per year

At BMC, research is always in progress.

Learn more biomedcentral.com/submissions 